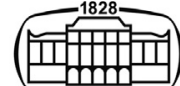

AKADÉMIAI KIADÓ

UNIVERSITY of DEBRECEN

International Review of Applied Sciences and Engineering

12 (2021) 1, 19-28

DOI:

$10.1556 / 1848.2020 .00110$

(c) 2020 The Author(s)

ORIGINAL RESEARCH PAPER

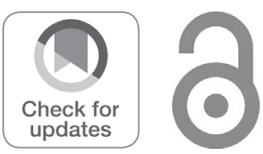

\section{Occupational, health and safety situation at small and medium enterprises in Kosovo, contextual factors, barriers, drivers and intervention process}

\author{
Mimoza Dugolli*
}

Faculty of Architecture, University of Prishtina "Hasan Prishtina", Republic of Kosovo

Received: February 25, 2020 • Accepted: May 24, 2020

Published online: February 9, 2021

\section{ABSTRACT}

This survey has been performed as part of a wider survey within the Western Balkan Small and Medium Sized Enterprises (SME) Competitiveness Support Project. It presents the current situation of occupational health and safety (OHS) management at 18 SMEs in Kosovo. SMEs in the Republic of Kosovo are facing many difficulties in identifying the real need for interventions, recruiting adequate professional staff to support their activities in OHS. Exposed to an opened market under the regional and international competition, their sustainability has become more difficult and their financial fragility leads very often to the ignorance of OHS issues within their organization.

The first objective of this research aimed to understand the OHS contextual factors, barriers and drivers based on the current practice of SMEs in Kosovo. The second objective was to find out if the OHS "ideal intervention process" is applicable to achieve improvements for SMEs in Kosovo. Data collection was expedited through internal documents review, site visits and questionnaires. The statistical data were subject to descriptive analyses and inferential statistics. The findings showed that the contextual factors which influence the intervention process, were of participatory nature, cognitive and physical workplace environment, while the perceived barriers were mainly coming from lack of resources and information. Finally the features of OHS "ideal intervention process" were analyzed and compared for applicability to the SMEs in Kosovo and several interventions in this regards were proposed.

\section{KEYWORDS}

Contextual factor, Kosovo, Occupational Health and Safety, interventions, SMEs

\section{INTRODUCTION}

Occupational health and safety (OHS) aims at protecting workers' health and welfare by adapting the working places to them and by promoting physical, mental and social welfare. According to International Labor Organization, using data of 2020, more than 2.78 million people die as a result of occupational accidents or work-related diseases. In addition, there are 374 million non-fatal work related injuries each year, resulting in a vast and economic burden estimated at $3.94 \%$ of global Gross Domestic Product.

The European Agency (EU - OSHA), on the other hand, acknowledges EU member states have nearly 19 million Small and Medium Sized Enterprises (SMEs) employing 75 million people and contribute to approximately $82 \%$ of all occupational injuries.

In the Republic of Kosovo, SMEs represent $79.6 \%$ of employees engaged in the private sector and $62.2 \%$ of the total workforce. Based on their sectors, the largest number of enterprises in Kosovo [1] belongs to sectors as presented in Table 1.

Literature classifies small to medium sized enterprises (SMEs) those having between 10 and 50 employees $[2,3]$. SMEs have been classified into the micro-enterprise ( $<10$ staff), the 
Table 1. Enterprises in Kosovo by sectors

\begin{tabular}{lc}
\hline Sector & Percentage (\%) \\
\hline Trade & 45.4 \\
Services & 14.8 \\
Processing Industry & 13.9 \\
Accommodation and food & 10.4 \\
Construction & 8 \\
Transport and storage & 3.8 \\
Information and communication & 2.8 \\
Mining and quarrying & 0.5 \\
Water supply, sanitation, waste and & 0.4 \\
$\quad$ land rehabilitation & \\
Electricity supply, gas and AC & 0.2 \\
\hline
\end{tabular}

small enterprise (10-50 staff), and the medium sized enterprise $(<250$ staff). However, evidence shows that SMEs are the main contributors to the high incidence of serious injuries and fatalities [4].

SMEs in the Republic of Kosovo are facing many difficulties in recruiting adequate professional human resources to support their activities. Being exposed to an opened market under the regional and international competition, their sustainability has become more difficult, especially for microenterprises. Their financial fragility leads very often to the ignorance of OHS issues within their organization.

When it comes to human resources and OHS, small businesses most of the time have no sufficient knowledge, time and resources [5] to address properly related issues. These concerns usually are not unique when considering OHS. In general, small businesses tend to operate without formal work procedures [6] and without administrative support [7]. In addition, the relative exposure to risk that causes the workplace accidents and injuries, are present at much higher levels among SMEs since they tend to operate in a more hazardous working environment than larger organizations. The literature says that several aspects of the working environment were related to firm size, with ergonomic, physical and chemical hazards, therefore the risk scale is significantly greater in SMEs compared to large firms [8].

A large number of employees engaged in the private sector at SMEs are working without regular working contracts. Consequently, they are not covered by health insurance, have no rights for paid sick leave nor receive any financial support to cover medications or healing when they are injured in their working places. Often, they work after working hours, during the weekends, night shifts and usually do not get compensated with appropriate tariffs, as foreseen by Law. These prolonged working schedules increase the risk for injuries or accidents as a result of work pressure, tiredness and fatigue. In addition, most cases of injuries and accidents at work are caused by the inability to fully understand the working process and automated production lines and because they usually do not undergo adequate trainings.

In Kosovo there is no accurate data available on workplace accidents, injuries or financial expenditures that SMEs have had for the compensation of such incidents. However, recently SMEs are becoming subject to rigorous monitoring by Government authorities and Labor Associations, therefore are bound to ensure their employees have proper working contract, and to improve safety conditions. On the other hand, SMEs are having difficulties in properly addressing all OHS issues due to lack of information and finding proper approach on successful OHS improvements. As a consequence, SMEs more and more are ending up paying financial compensations to their injured or sick employees due to litigations, which further weakens their financial situation.

\section{PROBLEM SETTING}

For SMEs, the improvement of safety conditions is a very important task. This improvement requires the implementation of effective OHS interventions [9-11]. Guido et al. [12] defines OHS intervention as an attempt to improve health and safety conditions in workplaces by means of targeted activities and initiatives.

The researchers have proposed complex frameworks of interventions driven by the lack of effectiveness of OHS activities. Cagno et al. [13] proposed a model for the design of OHS interventions that considers the contextual factors, the mechanisms affecting the implementation of interventions, and barriers and drivers for intervention process. Many studies propose different ways of designing, implementing, controlling and evaluating interventions. However, the common approach of these studies underlies the specific recommendations that can be applicable for creating an "ideal intervention process". Several Authors suggest that the ideal interventions process is defined as participatory within the company, qualitative, regulation based, and experience driven.

The SMEs chosen for this research present the sectors of production of plastic goods, production of furniture, manufacture of carpentry, medical care, manufacture of metal structures, manufacture of furniture and glass, sanitary equipment wholesale, dairy products wholesale, construction, agriculture wholesales, real estate agencies, manufacture of concrete and construction products, food, beverages and tobacco wholesale and cosmetics retail. The idea of this wide sectorial selection was to explore the situation of SMEs of most representative sectors in Kosovo.

The first objective of this research is aimed at understanding the contextual factors, barriers and drivers based on current OHS practice of 18 SMEs of various sizes and sectors in Kosovo. The second objective is to find out if the "ideal intervention process" from the literature review works for SMEs in Kosovo. To sum up, the research questions that this study aims to answer are:

1. What are the main contextual factors that influence the OHS performance at SMEs in Kosovo?

2. What are the barriers and drivers that influence the implementation of safety management system at SMEs in Kosovo? 
3. Does the features of ideal intervention process work for SMEs in Kosovo?

\section{LITERATURE REVIEW}

SMEs contribute significantly to the growth of economy. They are often even considered as the "backbone of economic growth". In developed countries, $65 \%$ of the total number of employees are generally accounted to be employed by SMEs [14].

The SME management is mainly responsible for the implementation of safety-enhancing systems and the development of a safety-oriented culture. Safety leadership motivates team members to work harder, to work efficiently and to take ownership of responsibility for safety performance [15]. In order to reduce the accidents at the workplace and promote safety among management and employees it is required to develop and sustain safety leadership. Increasing attention to safety leadership in various industries will result in increased organizational safety effectiveness [16]. Many previous studies that have examined models of leadership behavior in managers and supervisors claims that leadership has been fully implicated in safety issues at their enterprises. [17-20] defined safety leadership as "the process of interaction between leaders and followers, through which leaders can exert their influence on followers to achieve organizational safety goals under the circumstances of organizational and individual factors".

Despite the economic distinction, SMEs are characterized also by their nature, organizational factor and industry dynamism. It is very difficult to separate the safety management practices and other aspects of running small businesses [21, 22]. SMEs usually prefer to use verbal communication as opposed to written and in this way they cause lack of formal documentation and system, limited knowledge of OHS regulations, acts, limited knowledge of hazards and health effects.

The literature has been analyzed also with a focus on interventions concerning the contextual factors and barriers. Masi [9] refers to contextual factors as "factors that are not directly related to performance or behavior of the workers, but are expected to influence the performance of behavior substantially". As Pedersen [23] has stated in his research, the same intervention can have different outcomes related to different contextual factors.

Barriers can be considered as spin-off of contextual factors [12]. They count all those factors that are not directly involved in workplace safety interventions but significantly affecting the outcome of interventions [24]. By identifying the perceived barriers during this survey, the main drivers that contributed to the creation of the barriers were also identified.

In regard to intervention process, some authors emphasize that it has two different meanings. The first is that intervention should involve different participants within the company: the OHS practitioners, the management and the workers. The second meaning is that the interventions should be designed by involving participants outside the company, such as: government, regulators, and associations, company management, staff and the work and technological system.

Masi [9] defined the OHS interventions process as participatory within the company, qualitative, regulation based and experience driven. Therefore, based on contextual factors, barriers and drivers identified in this survey, the OHS interventions will be analyzed in order to check if suggested "Ideal intervention process" would be applicable among SMEs in Kosovo.

\section{OHS REGULATORY FRAMEWORK IN KOSOVO}

The main Legislative act of the Republic of Kosovo is the Constitution of Republic of Kosovo, which has the highest legal force among other legal legislations. It guarantees citizens the right to safe and healthy working conditions. The Labor Law determines the basic duties, rights and responsibilities of employers and employees in terms of labor protection. It sets the rules and procedures for the recruitment process, regulates the protection of rights of employees, from the recruitment phase and onwards. Health and Safety Law contains the general principles for occupation risk prevention and elimination of risks for improvement of health and safety level at working places. Other Regulations supplement the occupational safety and health provisions of the Health and Safety Law, however, the practical implementation has not been fully applied, especially by small and medium enterprises. Lack of proper monitoring of the applicability of these regulations by the responsible authorities has contributed to the ignorance of health and safety issues by most of the employers within their organizations.

In regard to other general safety measures related to fire protection, and protection from natural disasters, the Law on fire protection applies to all categories of the buildings and defines the responsibilities related to fire protection plans and measures to be taken from the building's owners. The fire protection measures and elaboratations are closely linked to the building permits and use certificates for the new buildings while also for existing buildings, they set the criteria for improvement and protection measures on fire hazards.

However, most of the regulations are applied for the new facilities, while many businesses are working on rented or old facilities that were not primarily designed for specific types of works. Therefore, the required technical standards or safety measures are rarely applied. Health and Safety Law provisions apply to public, private and private-public sector as well as central and local government administration with an aim to improve the level of safety and health of employees at work. The monitoring of practical implementation of this Law and related Regulation from all 
sectors falls under authority of the Ministry of Labor and Social Welfare, of the Labor Inspectorate as an independent body, within this Ministry. However, the low number of inspectors engaged to inspect the H\&S Law Implementation is not proportional with the number of registered SMEs, resulting in ineffective monitoring. In addition, due to the lack of $\mathrm{H} \& \mathrm{~S}$ professionals among the Labor Inspectorate, their requirements during the inspections were focused mainly on working contracts and working hours. The adequate H\&S trainings, working environment, personal protective equipment, the proper qualification and licenses, protective measures and other, were mainly ignored and not monitored by the Labor Inspectors. Except for financial issues, this contributed even more to deviation from the main $\mathrm{H} \& \mathrm{~S}$ goals, within the enterprises.

\section{MATERIAL AND METHODS}

The survey was carried out in 18 randomly chosen SMEs located in Kosovo to study their OHS practices using mixed methods, research, design, and results that can be translated into practical ends. The statistical data were subjected to descriptive analyses and inferential statistics. The descriptive statistics were applied for the part of the survey that would clearly describe contextual factors, and we do not need to make conclusions beyond the data we have analyzed. However, when analyzing the barriers, we used inferential statistics, as those are "perceived barriers" and are not expected to perfectly represent the group of data.

Initially, the OHS management practice has been reviewed by analyzing the OHS documentation in place and consisted of several discussions and meetings with the management and executives of the SMEs. A questionnaire survey and site observation were performed to practically inspect the current OHS practices among employees. In addition, a questionnaire was shared with the management of the SMEs in order to identify the main barriers, as they consider, that prevent them from being in compliance with OHS legal requirements. The survey process was divided into several steps:

1. A review of the company's OHS documentation and written records for key safety indicators. The assessment of specific elements was done according to set criteria and given scores from 0 to 3 as follows, with guidance notes given.

0 - Not done.

1 - Done poorly/considered as unimportant/little evidence.

2 - Done acceptably/considered as important/some evidence.

3 - Done exceptionally/considered as very important/ good evidence.

The analyzed documents related to the company's H\&S effort: Workplace risk evaluation, H\&S statement for working places, testing reports for environmental microclimatic conditions at the workplaces, hazard materials register, H\&S training records, Fire Protection Plans, Fire Protection trainings, Emergency Plans, etc.

2. An observation/inspection tour was performed including informal questions to supervisors and employees, to verify both the observation and other data.

The assessment of specific elements was done according to set criteria and given scores from 0 to 3 as follows, with guidance notes given.

0 - Not managed.

1 - Applied poorly.

2 - Applied acceptably.

3 - Applied exceptionally.

During this part, a visual assessment was undertaken including: hazards, workplace layout and cleanliness, personal protective equipment (PPE) usage and storage, environmental conditions, condition of plant/equipment/ buildings, safety information and signs displayed in general and at workstations, etc.

Many intervention models nowadays have been proposed through the description of the contextual factors [23]. Therefore, written documentation review and visual inspection performed during this survey enabled us to understand which contextual factors characterize the SMEs that were subjects of this survey.

3. Drivers and barriers can identify, as well, the contextual factors significantly affecting the outcome of the interventions, therefore a questionnaire was designed to solicit the respondents on the degree of relevancy of the 5 barriers. A five point Likert scale was used starting from 1) Relevant to 5) Extremely relevant.

\section{BACKGROUND INFORMATION OF THE SMES SELECTED FOR STUDY}

In all 18 cases, the selected sectors were: production of plastic goods, production of furniture, manufacture of carpentry, medical care, manufacture of metal structures, manufacture of furniture and glass, sanitary equipment wholesale, dairy products wholesale, construction, agriculture wholesale, real estate agencies, manufacture of concrete and construction products, food, beverages and tobacco wholesale, cosmetics retail. Figure 1 describes the scale-wise

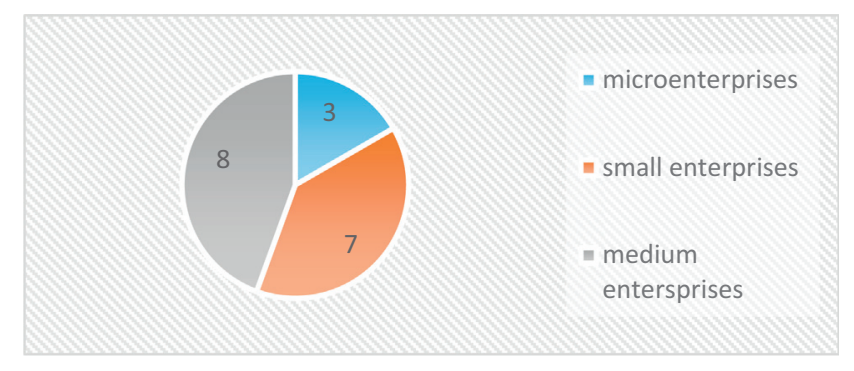

Fig. 1. Distribution of enterprises according to scale 


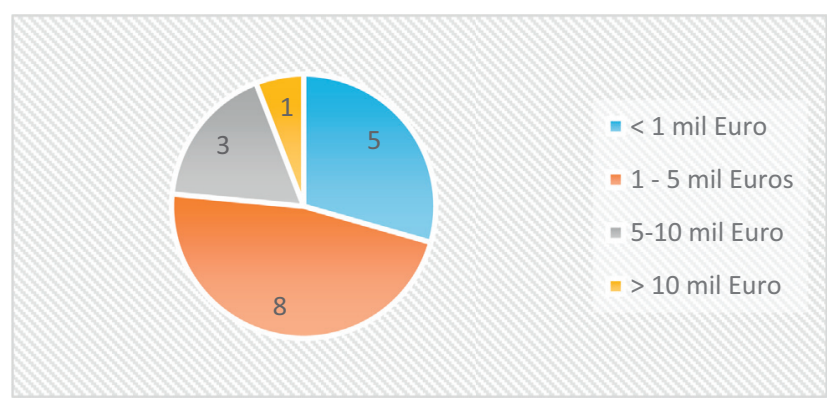

Fig. 2. Turnover range of the enterprises

distribution of the visited enterprises. Out of 18 visited enterprises, two were micro enterprises with less than 10 employees, seven were small scale enterprises with 10-50 employees, and eight were medium scale with a number of employees between 50 and 250 .

Out of the 18 enterprises visited, as shown in Fig. 2, five of them had a turnover of up to 1 million euros per year, eight of them had a turnover from 1 to 5 million euros, three had a turnover of 5-10 million euros per year and one had a turnover of more than 10 million euros per year.

\section{RESULTS}

The checklist applied during the documents review is presented in Table 2.

Regarding the workplace hazard identification and risk assessment and management, the majority of the employers answered that they did not know or did not see it as important, although the H\&S Law obliges them to perform the mentioned activities and to prepare the H\&S Statement for each workplace within the enterprises. There are exceptional sectors such as medical care, which have prepared risk assessment and management plan, but mainly due to radiation, chemical or biological related risks. The mechanical, physical risks arising from other activities are not considered.

These factors determine the subclass of the contextual factor, which is defined as the "Participation" [12]. The "Participation" has the meaning of involvement of different actors within the company, and involvement of the actors outside the company when considering the interventions for OHS improvements.

The training, skills, workers' behavior experience, resistance and/or attitude of workers represent the "Cognitive factors" as contextual factor. The features of the employees or persons that affect performance or learning are known to be cognitive factors. These factors serve to modulate performance such that it may improve or decline [25].

In regard to the training, most of the employers have not provided any to their employees, although they recognize its importance. A small percentage of them confuses the H\&S training with technical training when working with automated production process or they confuse OHS trainings with fire safety trainings. Here, we can also notice some sectorial differences. The enterprises, whose main working activities do not require high qualified workers such as glass production, production of plastic products, or selling agricultural products, do not see the H\&S trainings as an important issue. Better situation is observed at enterprises with more complex production lines such as furniture production, and production of metal structures.

Monitoring of the work place microclimatic conditions was not performed by any of the SMEs. Some technical measures were found to have been taken into consideration, especially at health care enterprises, such as protection of the areas from radiation. However, no monitoring devices were found to be installed to check the level of radiation released from the areas where such activity was performed. Although considered as desperately needed, monitoring of dust levels or level of chemicals released during the production process during furniture production, window production, were not even considered as important by the employers.

These factors represent the subclass of contextual factors identified as "Physical work environment". By modifying working conditions many companies improved safety conditions in the enterprise and avoided work-related injuries.

Regarding the Fire Safety and Emergency Preparedness, $54 \%$ of the enterprises have not done any steps toward addressing this issue. The Fire Protection Elaborates are required only during the procedures for application for the construction of the new buildings. However, half of the enterprises interviewed were operating in old buildings, consequently they did not have any fire safety studies,

Table 2. Current occupational health and safety checklist

\begin{tabular}{|c|c|c|c|c|}
\hline OHS Checklist & $\begin{array}{l}\text { Not } \\
\text { done }\end{array}$ & $\begin{array}{c}\text { Done poorly/considered } \\
\text { as unimportant/little } \\
\text { evidence }\end{array}$ & $\begin{array}{c}\text { Done Acceptably/ } \\
\text { considered } \\
\text { as important/some } \\
\text { evidence }\end{array}$ & $\begin{array}{c}\text { Done exceptionally/ } \\
\text { considered as } \\
\text { important } \\
\text { good evidence }\end{array}$ \\
\hline Hazard Identification & $72 \%$ & $13 \%$ & $15 \%$ & $0 \%$ \\
\hline Risk Assessment and management & $81 \%$ & $10 \%$ & $9 \%$ & $0 \%$ \\
\hline Measuring Workplace hazards & $100 \%$ & $0 \%$ & $0 \%$ & $0 \%$ \\
\hline $\begin{array}{l}\text { Fire Safety and emergency } \\
\text { preparedness }\end{array}$ & $54 \%$ & $30 \%$ & $13 \%$ & $3 \%$ \\
\hline Medical checks and record keeping & $80 \%$ & $6 \%$ & $14 \%$ & $0 \%$ \\
\hline
\end{tabular}

Note: The OHS management system was investigated from the employer's perspective. 
documents, or emergency procedures. Their understanding mainly is that since they have placed a certain number of fire extinguishers within the building, they have addressed the issue, even though during the visual inspection many times the inspection of equipment was over the due date, in hidden places and sometimes hanging so high that it would be very difficult to use it in case of fire. During the documentation review, it was also noticed that regular medical check was missing. Despite the initial medical check required when entering into working contract with enterprise, no other health data were found within the employees' files.

The factors mentioned above represent the contextual factors related to "Information, safety culture and leadership". According to Fernández-Muñiz [26], the managers' commitment is expressed by showing a continuous interest for the working conditions of their employees and by getting personally involved in the activities and by the implementation of best safety practices.

After the review of the documents and policies in place, an observation/inspection tour was performed to verify the $\mathrm{H} \& \mathrm{~S}$ measures implemented in practice. Many hazards were noticed in the area of $57 \%$ of the SMEs. Housekeeping was not maintained, and such the workplaces were not kept clean. The walking areas were not cleared and free of obstacles. This would increase the risk of trips and slips during the work performance. In most of the cases, there was no functional ventilation system found and in some of the cases very strong smells of chemicals used on the production process were perceived. Workplace layout were managed at acceptable levels mainly in the medical health and wholesales SMEs, while in the production process, the workplace layout was affected by the type of production line and equipment. During the visit, the employers were asked if they were to change the working layout if they had a chance to modify the workplace based on the OHS surveillance, and most of them declared that they would not do so as it would create additional costs to adapt required infrastructure needed. The employees were not wearing personal protective equipment (PPEs) in $70 \%$ of the enterprises visited. A minority $(30 \%)$ of them were mainly wearing seasonal working clothes and working boots, without required hand and face protection. When the employees were asked why, they claimed that they do not feel comfortable performing their activities sometimes when using PPE. Safety information and fire protection measures were missing in almost every enterprise. In the cases when the buildings had two separate entrances/exits, the secondary exits were covered with materials stored and other working materials and usually not distinguished with signs. The status of practical implementation of H\&S measures is presented in Table 3.

Drivers and barriers can be considered as spin-off of contextual factors [12]. They identify contextual factors involved in workplace safety interventions affecting fostering the outcome of interventions.

The most relevant barrier identified among the respondents is showed in Table 4, which has the highest mean value. The results show that the cost for implementation of OHS is the main challenge to SMEs as they operate in a very unstable economic environment. They consider the investments required for employee health insurance, trainings, risk assessment and trainings as a burden to their very fragile budget. The management commitment is the second barrier to the implementation of OHS, which is directly related to the first barrier. Having in place internal policies and regulations requires outsourced services from licensed enterprises, as indicated by OHS legislation. Poor safety culture and a lack of human resources to implement OHS has shown that they are very closely linked, as some SMEs hesitate to engage experts as a special working position within their organization to perform health and safety duties. What they usually apply is, adding some very general activities to any employee among other duties, which contributes to avoiding most of the time $\mathrm{H} \& \mathrm{~S}$ issues and considering this one as secondary activity.

Table 4. Perceived barriers to OHS management among SMEs in Kosovo

\begin{tabular}{lcc}
\hline No & $\begin{array}{c}\text { Barriers to improve safety } \\
\text { performance among SME }\end{array}$ & Mean score \\
\hline 1 & Cost & 3.78 \\
2 & Lack of Human Resources to & 3.33 \\
& implement safety & \\
3 & Lack of H\&S trainings & 3.10 \\
4 & Lack of management commitment & 3.42 \\
5 & Lack of strict enforcement from & 3.12 \\
6 & $\quad$ Government Authorities & \\
7 & Poor safety culture & 3.37 \\
\hline
\end{tabular}

Note: This table presents survey data

Table 3. Observed status of OHS in practice applied at SMEs

\begin{tabular}{lcccc}
\hline H\&S measures on practice & Not managed & Managed poorly & Managed Acceptably & Managed exceptionally \\
\hline Hazards at Working places & $57 \%$ & $23 \%$ & $15 \%$ & $5 \%$ \\
Workplace layout & $19 \%$ & $73 \%$ & $8 \%$ & $0 \%$ \\
Personal protective equipment & $70 \%$ & $30 \%$ & $0 \%$ & $0 \%$ \\
Environmental conditions & $60 \%$ & $20 \%$ & $20 \%$ & $0 \%$ \\
Safety information and signs & $80 \%$ & $10 \%$ & $10 \%$ & $0 \%$ \\
Fire protection measures & $90 \%$ & $7 \%$ & $3 \%$ & $0 \%$ \\
\hline
\end{tabular}

Note: This table presents observation data 
Therefore, to sum up, the perceived barriers presented above, belong to different categories but can be grouped into two main levels:

- Resources problems (lack of time, lack of financial resources, lack of human resources),

- Information problems (ineffective information, lack of awareness of OHS, lack of technical support).

\section{DISCUSSION}

The results of this survey enabled an identification of some of the contextual factors and barriers for OHS implementation at SMEs in Kosovo. These factors belong to three main groups as presented below:
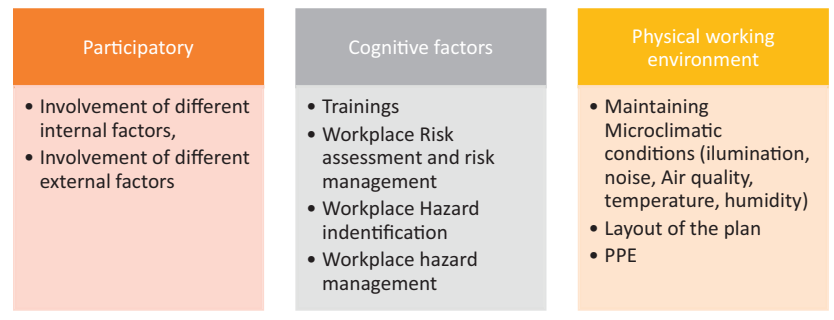

Based on literature review, these factors are considered not only as contextual but also as barriers. Whysall et al. [27] considered that management involvement in safety is very important. Our results showed that the Management of the SMEs, in most of the cases, did not take any special steps to identify workplace hazards, perform risk assessment and manage those risks. In practice, this is the first step toward an intervention process for effective OHS management. Masi et al. [9] states that there are three factors within the company that should actively be involved in OHS Interventions: the OHS practitioners, management and the workers. The OHS practitioners are people that regularly conduct OHS activities within the company. Their role is very important as their experience combines the inputs on technical, human and organizational aspects. However, legal requirements in Kosovo do not oblige all SMEs (only SMEs with more than 50 employees) to engage such practitioners. Therefore considering their great role in the intervention process, this can be considered as a gap that needs to be addressed for SMEs in Kosovo.

Many authors [28-32] suggest that the involvement of the workers is also key to the successful implementation of OHS interventions. However, the SMEs employees in Kosovo usually are not highly qualified to be able to contribute to the overall improvement process within the Enterprise. In regard to the involvement of external factors, Rasmussen and Swedung [33] argue how an effective intervention depends on proper coordination of decision making at six different levels: the government, regulators, and associations, company, management, staff and the work and technological process. During the survey most of the time it was discussed that the main actions taken for OHS compliance are taken by fear of sanctions by control authorities. On the other hand, the control authorities most of the time are focused on the punishment of SMEs for any noncompliance rather than supporting the improvement process.

With the improvement of workers' awareness of safety and health, the attention to OHS will be increased. Montibeller et al. [34] claims that the reduction of human errors and managing controls is a strategic approach for improving performance of OHS. Training was one of the important contextual factors, identified as the way to make workers feel responsible for their actions. However, it can be concluded that this is linked to the management involvement in safety and leadership as the survey showed that the low \% of trained workers is a result of lack of time, resources and knowledge of management.

Most of the time the modification of the layouts and workplace conditions had a significant impact on the improvement of safety in the enterprise. However, this survey showed that many of the companies hesitated to improve or change the layout of the production halls, as this would incur additional expenses on infrastructure adaption. In all circumstances, when microclimatic conditions enable the thermal, hygienic and visual comfort for employees, this will increase the attention on working process and will decrease the possibility for injuries or unwanted events.

Going further, during this survey, the main perceived drivers that contributed to the first group of identified barriers (resources problems: lack of time, lack of financial resources, lack of human resources) were:

- Monetary incentives from central and local control authorities.

- Tailor made legislation for SMEs.

- Training programs for SMEs.

- Knowledge of effective interventions.

Related to the second group of perceived barriers (information problems: ineffective information, lack of awareness of OHS, lack of technical support), the identified drivers were:

- External support of OHS management by control authorities.

- Communication tools.

- Knowledge of effective interventions.

- Collaboration with customers, contactors, suppliers, etc.

In regard to interventions on OHS, the literature has been focused mostly on features of ideal interventions process. The researchers have provided extensive analyses of how interventions should be designed and evaluated. Most of these studies suggest individual approaches which are believed to be optimal, even though they neglect what actually works in professional practices. However, Masi et al [9] defined the intervention process as: participatory within the company, qualitative, regulation based, and experience driven. Based on identified contextual factors, barriers and drivers, we compared the features of interventions process 
which can be applied on the SMEs in Kosovo, discussed in the following.

\section{Participatory within the company}

Theoretical recommendations conclude that intervention process relies on the active participation of different actors within the company, starting from:

- The end users which are the rule of choosing materials, activities, and technology.

- Employees with their unique knowledge on some aspects of the jobs.

- OHS practitioners that work by guidelines coming from mandatory and voluntary standards, and

- Management with positive attitude toward health and safety.

Contextual factors identified in this survey showed that the external participation is also very important and would have significant impact on the intervention. The identified barriers showed that there was a lack of information related to OHS practices and issues, driven by the lack of communication tools and collaboration with different actors, which disabled a wide debate pointing out how and when would an effective OHS intervention be applied at SMEs.

Therefore, we can conclude that participation is a very important step of the intervention process for SMEs in Kosovo, consequently, it would have to begin with:

- Perception of importance of interventions from all actors - when the importance of intervention is perceived by managers, the needs of employees can be more accurately determined, and the errors will be avoided during working activities and other events.

- Confidence in chosen intervention - managers and employees must be confident that the chosen interventions are the adequate for the type of activity and business features. Employees need to have confidence in their management decisions and management needs to trust its employees that they are in line with business overall goals.

- Motivation and trust in management and in enterprise employee motivation is all about how engaged an employee is toward companies goals. The motivated employee is an asset for the company, therefore in achieving overall OHS improvement, this is one of the important steps the management should take.

\section{Qualitative approach}

Masi [9] states that qualitative approach characterizes the design, implementation and evaluation of interventions. The qualitative approach includes all the activities performed by OHS practitioners starting from the design of the interventions, implementation and evaluation. During the design phase this approach is used for scheduling the interventions and allocation of resources. The implementation process depends on particular intervention rather than systematic while the features of evaluation process depends on the availability of mandatory or voluntary standards.

However, considering that the legislation in Kosovo does not oblige SMEs under 50 workers to engage an $\mathrm{OHS}$ practitioner, this approach does not seem to be employed in SMEs in Kosovo. In addition, OHS practitioners in Kosovo are very limited as only recently they started to get certified on OHS by entitled authorities, a process which is also very general and does not produce any field related OHS practitioner. Other OHS specializations are not available in Kosovo and most of the times SMEs do not invest in specialized trainings for their personnel. Therefore, in our case, Qualitative approach is closely linked to Regulation based approach, discussed in the following.

\section{Regulation based}

This approach is based on compliance with national regulations. When the design of intervention or assessment of needs is done, always the decision making process is referring to regulations. Therefore the overall approach is "reactive" rather than "proactive". As the approach based on regulations is simple, this may lead to design of intervention only to fulfill legal requirement rather than to the needs of enterprises. OHS practitioners also will not be stimulated to look for the best solution available but they will focus on less expensive solutions. In this light, a pattern of intervention would be:

- The development of tailored legislation for SMEs or the modification of some aspects that might be considered as barriers for SMEs.

\section{Experience driven}

This approach allows some kind of process tailoring interventions based on the needs of the company. In addition, the OHS practitioners are aware of features of the company so they can use their knowledge and select the best options for OHS interventions. However, to use this approach it is necessary to render the theoretical knowledge of workers and OHS practitioners. This research has showed that among the contextual factors were identified cognitive factors - trainings as activities, whose aim is the functional coordination of OHS actions, namely educating and training activities as well as safety related policies. In this regard, at the SMEs in Kosovo the results have shown that very little attention is paid to training and education. In this regard a pattern of intervention should include:

- Design and implementation detailed training procedures by including new employees, temporary employees and those who are engaged as regular employees within the enterprise.

- Application of mandatory courses due to law requirements, and

- Application of voluntary safety courses to make workers more aware of safety. 


\section{CONCLUSIONS}

This survey, based on interviews, site visits and literature review, gives an overview of contextual factors for OHS intervention which characterizes the SMEs in Kosovo. The identified factors are of Participatory nature, Cognitive and Physical working environment. During this survey the perceived barriers that unable the improvements on OHS as well as drivers that lead to appearance of the perceived barriers have also been identified. The main barriers identified in this survey were lack of resources and information, driven by a set of internal and external factors. These factors are used to make comparative analyses to the interventions process suggested by different authors and literature explored for this purpose.

The main approach of process intervention for OHS improvement is compared to the contextual factors for cases of SMEs in Kosovo. The interventions which are proposed in order to address the gaps, are intervention on participatory processes such as: perception of importance of interventions from all actors, confidence in chosen intervention, motivation and trust in management and in enterprise. The Qualitative approach was found as not applicable for SMEs in Kosovo unless the legislation is not improved and modified in order to address issues that currently are considered as barriers for SMEs in Kosovo.

As for limitations of this study, the research was restricted to 18 cases as it was very challenging and hard to reach out to SMEs because the safety topic is still a very delicate topic. In this regard, it is recommended that future research should: (a) extend the number of SMEs; (b) extend the sectors; (c) focus on sectors with similar activities. Future research could compare more data and analyze the sectors separately to understand the specific intervention process for each sector as different risks can affect different sectors.

\section{REFERENCES}

[1] MTI. Strategjia per zhvillimin e NVM ne Kosovë 2012-2016 me vizion ne 2020. Prishtina: The Agency for SME support, 2011.

[2] J. Boarley, "A health and safety system which works for small firms," J. R. Soc. Health, vol. 117, no. 4, pp. 211-5, 1997.

[3] D. Walters, Health and safety in small enterprises. European strategies for managing improvement: P.I.E. Peter Lang, 2001, pp. 211-5.

[4] Claire Mayhew MQRF, "The effects of subcontracting/outsourcing on occupational health and safety : survey evidence from four Australian Industries," J. Saf. Sci., vol. 25, no. 1-3, pp. 163-78, 1997.

[5] E. Kevin Kelloway CLC, Occupational health and safety for small and medium enterprises. 1st ed. E Kevin Kelloway CLC, editor. UK: Edward Elgar Publishing, Limited Inc. ISBN-13: 9781848446694, ISBN-10: 1848446691; 2011.

[6] F. Curtis Breslin, "NKPB. Effectiveness of health and safety in small enterprises: a systematic review of quantitative evaluations of interventions," J. Occup. Rehab., vol. 20, no. 2, pp. 163-79, 2009.
[7] M. Joan, and E. M. Eakin, "Reframing the evaluation of qualitative health research : reflection on a review of appraisal guidelines in the health sciences," J. Eval. Clin. Pract., 2003.

[8] P. Hasle and O. H. Sørensen, "When health and safety interventions meet real-life challenges, policy and practice in health and safety," J. Pol. Pract. Health Saf., vol. 9, no. 1, pp. 3-16, 2016.

[9] D. Masi, E. Cagno, and G. J. Micheli, "ECGJ,LM. Developing, implementing and evaluating OSH interventions in SMEs: a pilot exploratory study," Int. J. Occup. Saf. Ergon. JOSE, vol. 20, no. 3, pp. 385-405, 2014.

[10] L. S. Robson, et al. "The effectiveness of occupational health and safety management system interventions: a systematic review," J. Saf. Sci., vol. 45, no. 3, pp. 329-53, 2007.

[11] S. Lynda, et al. "A systematic review of effectiveness of occupational health and safety training," Scand. J. Work Environ. Health, vol. 39, no. 3, pp. 193-208, 2012.

[12] G. J. L. Micheli, E. Cagno, and A. Calabrese, "The transition from Occupational Safety and Health Interventions to OSH outcomes: and empirical analysis of mechanisms and contextual factors within small and medium sized enterprises," Int. J. Environ. Res. Public Health, vol. 15, no. 8, 2018 August.

[13] E. Cagno, G. J. L. Micheli, C. Jacinto, and D. Masi, “An interpretive model of occupational safety performance for small and medium enterprises," Int. J. Ind. Ergon., vol. 44, no. 1, pp. 60-74, 2014.

[14] J. Tonge, A Review of Small Business Literature, Part 1: Defining the Small Business. Working Paper Series WPS 025, 2001.

[15] A. O'Dea, "RF. Site managers and safety leadership in the offshore oil and gas industry," J. Saf. Sci., vol. 37, pp. 39-57, 2001.

[16] C.-S. Lu and C.-S. Yang, "Safety leadership and safety behaviour in container terminal operations," J. Saf. Sci., vol. 48, no. 2, pp. 123-34, 2010.

[17] J. Barling, C. Loughlin, and E. K. Kelloway, "Development and test of model linking safety specific transformational leadership and occupational safety," J. Appl. Psychol., vol. 87, no. 3, pp. 488-96, 2002.

[18] D. Zohar, "Safety climate: Conceptual and measurement issues," in Health and Safety in Organizations, J. C. Quick, L. E. Tetrick, Eds., et al. American Psychological Association, 2003, pp. 201-30. Available at: https://psycnet.apa.org/record/2002-18427-006.

[19] T.-C. Wu, C.-H. Chen, and C.-C. Li, "A corelation among safety leadership, safety climate and safety performance," J. Loss Prev. Process Industry, vol. 21, no. 3, pp. 307-18, 2007.

[20] E. K. Kelloway, J. Mullen, and L. Francis, "Divergent effects of transformational and passive leadership performance," J. Occup. Health Psychol., vol. 11, no. 1, pp. 76-86, 2006.

[21] S. J. Legg, K. Olsen, I. Laird, and P. Hasle, "Managing safety in small and medium enterprises," J. Saf. Sci., vol. 71, pp. 189-96, 2015.

[22] P. Hasle, H. J. Limborg, T. Kallehave, C. Klitgaard, and T. Rye Andersen, "The working environment in small firms: responses from owner-managers," Int. Small Business J. Researching Entrepreneurship, vol. 30, no. 6, pp. 622-39, 2012.

[23] L. M. Pedersen, K. J. Nielsen, and P. Kines, "KJNPK. Realistic evaluation as a new way to design and evaluate occupational safety interventions," J. Saf. Sci., vol. 50, no. 1, pp. 48-54, 2012.

[24] C. V. Stolk, L. Staetsky, and E. Hassan, An Analysis of the Findings of the European Survey of Enterprises on NEw Emerging Risks. European Agency for Safety and Health at Work, 2012, pp. 1-58. 
[25] E. Roy, "Cognitive factors," 1st ed. Gellman M.D. TJR, Eds., New York: Springer, NY; 2013.

[26] B. Fernández-Muñiz, J. Manuel Montes-Peón, and C. José Vázquez-Ordás, "Safety Culture: analysis of the casual relationships between its key dimensions," J. Saf. Res., vol. 38, no. 6, pp. 627-41, 2007.

[27] Z. Whysall, C. Haslam, and R. Haslam, "Implementing health and safety interventions in the workplace: an exploratory study," Int. J. Ind. Ergon., vol. 36, no. 9, pp. 809-18, 2006.

[28] K. Noro and A. S. Imado, Participatory Ergonomics, London, UK, Taylor and Francis, 1991.

[29] S. J. Schurman, B. A. Silverstein, and S. E. Richards, "Desinging a curriculum for healthy work: reflection on the United Automobile, Aerospace and Agricultural Implement Workers general motors ergonomic project," Occup. Med., vol. 9, no. 2, pp. 283-304, 1993.
[30] A. G. Vredenburgh, "Organizational safety: which management practices are most effective in reducing employee injury rates?," $J$. Saf. Res., vol. 33, no. 2, pp. 259-76, 2002.

[31] P. Loisel, L. Gosselin, P. Durand, J. Lemaire, S. Poitras, and L. Abenhaim, "Implementation of a participatory ergonomics program in the rehabilitation of workers suffering from subacute backpain," Appl. Ergon., vol. 32, no. 1, pp. 53-60, 2001.

[32] J. A. Hess, S. Hecker, M. Weinstein, and M. Lunger, "A participatory ergonomics interventions to reduce risks factors for low back disorder in concrete laborers," J. Appl. Ergon., vol. 35, no. 5, pp. 427-41, 2004.

[33] J. Rasmussen and I. Svedung, Proactive Risk Management in a Dynamic Society Sweden. Borås: Sjuhäradsbygdens Tryckeri, ISBN: 91-7253-084-7, 2000.

[34] G. Montibeller and D. von Winterfeldt, "Cignitive and motivation biases in decision and risk analysis," Risk Anal. J., vol. 35, no. 7, pp. 1230-50, 2015. 